\title{
Uterine B-cell lymphoma in two dogs - a case report
}

\section{Ladislav Novotny ${ }^{1}$, Frances Taylor ${ }^{2}$, Katherine Claxton $^{3}$, Jana Dudova ${ }^{4}$, Daren Hanshaw ${ }^{1}$, Jan Misik ${ }^{5,6}$}

\author{
${ }^{1}$ Finn Pathologists, Weybread, United Kingdom \\ ${ }^{2}$ Calder Vets, Dewsbury, United Kingdom \\ ${ }^{3}$ The Dam Vet Centre, Selby, United Kingdom \\ ${ }^{4}$ Veterinary Clinic Na Kopci, Opava, Czech Republic \\ ${ }^{5}$ University of Defence, Faculty of Military Health Sciences, Department of Toxicology and Military Pharmacy, \\ Hradec Kralove, Czech Republic \\ ${ }^{6}$ University Hospital Hradec Kralove, Biomedical Research Centre, Hradec Kralove, Czech Republic
}

Received February 3, 2017

Accepted May 31, 2017

\begin{abstract}
Uterine lymphoma is rare in the dog, in other animal species, and in humans. The lymphoma in the two female dogs presented as a primary tumour of uterine tissue and was classified as diffuse centroblastic B cell lymphoma. Terminally, the uterine lymphoma metastasized to various organs in one of the dogs, despite chemotherapy. This case study describes a very rare form of canine lymphoma and suggests to include lymphoma in the differential diagnoses in bitches with uterine masses.
\end{abstract}

Urogenital medicine, neoplasia, canine, uterus, lymphoma

Lymphoma is the most common haematopoietic malignancy in dogs and represents $7-24 \%$ of all neoplasms, and $83 \%$ of haematopoietic malignancies (Kaiser 1981; Moulton and Harvey 1990). According to the most recent World Health Organisation (WHO) classification system, the majority of canine lymphomas can be divided into several common subtypes: diffuse large B cell lymphoma, marginal zone lymphoma, peripheral $\mathrm{T}$ cell lymphoma not otherwise specified, nodal $\mathrm{T}$ zone lymphoma, and $\mathrm{T}$ lymphoblastic lymphoma. Diffuse B cell lymphoma is further subdivided into centroblastic, in which the cell nuclei have multiple nucleoli (DLBCL-CB), and immunoblastic with a single central prominent nucleolus (DLBCL-IB) (Valli et al. 2011).

Numerous different chemotherapy protocols have been described for the treatment of canine lymphoma, including the multi-agent CHOP-based (C-cyclophosphamide; H-hydroxydaunorubicin; O-vincristine; P-prednisolone) protocol. Complete remission rates of $72-92 \%$ have been reported, and first remission durations range from 8-12 months (Garrett et al. 2002; Morrison-Collister et al. 2003; Burton 2013 et al; Mutz et al. 2015).

The commonest anatomical presentation for cases of canine lymphoma is multicentric lymphoma, although specific anatomical presentations of canine lymphoma such as renal, alimentary, cutaneous, and hepatic are well recognized (Moulton and Harvey 1990; Risbon et al. 2006; Fontaine et al. 2010; Withrow et al. 2012; Taylor et al. 2014; Carrasco et al. 2015). Reported cases of canine lymphoma with involvement of the female genital tract, and cases of primary uterine lymphoma are rare (Ko et al. 2013).

The following are two cases of canine DLBCL-CB lymphoma that appear to have arisen as primary tumours within the uterus.

\section{Case histories}

Case No 1. was a female German Short Hair Pointer, 15 months old. At routine ovariohysterectomy, the uterus was found to have a grossly abnormal nodular appearance 
(Plate V, Fig. 1A) and was submitted for histopathology. On submission, the uterus was grossly thickened, with irregular swellings in the horns and body that were slightly purple in colour.

Histopathologically (Plate V, Fig. 1B), the endometrium and myometrium were expanded by dense, monomorphic sheets of intermediate-sized to large round cells with minimal cytoplasm and a high nuclear to cytoplasmic $(\mathrm{N}: \mathrm{C})$ ratio. Nuclei were round to oval with multiple nucleoli and a high mitotic rate (3-6/high power field; HPF). Occasional apoptotic cells were seen. The infiltrate did not extend to the mesometrium. The left ovary was of normal morphology. In the right ovary, there were two corpora lutea and one of them was focally expanded by a monomorphic population of neoplastic lymphocytes of the same morphology as described in the uterus. Staining of these sections using antibodies to B and T cell markers (CD79a and CD3 antigens, respectively) revealed a majority of CD79a positive neoplastic cells (Plate V, Fig. 2B), consistent with classification as a centroblastic diffuse large B-cell lymphoma (DLBCL-CB).

Following the histopathological diagnosis, tumour staging was performed. On clinical examination, a cutaneous mass adjacent to the right caudal nipple was apparent, measuring $1 \mathrm{~cm}$ in diameter. Abdominal ultrasonography showed enlarged intra-abdominal lymph nodes and a hyperechoic spleen. There was no radiographical evidence of lymphoma in the thorax. Fine needle aspiration biopsy of an enlarged intra-abdominal lymph node, spleen, and the cutaneous mass adjacent to the right caudal nipple (Plate V, Fig. 2A) was consistent with the involvement of DLBCL-CB in these organs. Blood smear examination did not prove leukaemia.

The dog was treated using a CHOP chemotherapy protocol. Repeat abdominal ultrasonography was not performed, but the nipple mass regressed completely during week 1 of chemotherapy and no clinical deterioration was noted. At week 11 of the chemotherapy protocol, the dog presented apparent radial nerve paralysis of the right forelimb, and at week 12 there was clinical evidence of a uveal tumour involvement of the left eye. The dog also showed progressive depression, suggesting central nervous system (CNS) disease involvement. The dog was euthanized at the owners' request, and histopathology of post mortem samples confirmed the presence of DLBCL-CB lymphoma in the spleen, liver, mesenteric lymph nodes, and in the ciliary body and iris (Plate V, Fig. 2C, D). The brain and the spinal cord were not sampled.

Case No 2. was a female Bernese Mountain Dog, 8 years old. The dog was presented with weakness of the pelvic limbs, and anorexia ultrasound examination revealed an enlarged uterus with gas occupying the uterine horns (pneumometra) and splenomegaly. No enlargement of other organs or lymph nodes was seen. Radiography of the chest was unremarkable. Grossly, the uterine horns showed multiple nodular swellings (Plate V, Fig. 1C). Pre-operative blood chemistry and haematology were unremarkable. Ovariohysterectomy and splenectomy were performed.

Histopathology (Plate V, Fig. 1D) revealed the endometrium and myometrium expanded by dense, monomorphic sheets of intermediate-sized to large immature lymphoid cells with scarce cytoplasm and a high N:C ratio, similar to Case 1 . Nuclei were round to oval with multiple enlarged nucleoli and 2-4 mitoses per HPF. Scattered apoptotic cells were present. The spleen was diffusely infiltrated by sheets of round cells of the same morphology as observed in the uterus. Immunohistochemistry revealed a predominant population of CD79a positive neoplastic cells, consistent with centroblastic large B-cell lymphoma.

Clinically, there was marked improvement after surgery, but 10 days later multiple tumours appeared within the mammary glands and periorbital skin. No other treatment was administered. The dog deteriorated two weeks post-operatively and was euthanized upon the owner's request. 


\section{Discussion}

Reported cases of canine lymphoma presenting with involvement of the female genital tract, and cases of primary uterine lymphoma, are rare (Ko et al. 2013). Uterine lymphomas have been described uncommonly in other animal species (Tanaka et al. 2003; Burton et al. 2010; Claes et al. 2015; Diaz-Delgado et al. 2015), and in cattle they are most commonly found in association with the bovine leukaemia virus (Olson and Baumgartener 1976; Burton et al. 2010).

Cases of human uterine lymphoma are also rare (Bellevicine et al. 2014; Hadi et al. 2015). Although a variety of different histological subtypes have been described (Komaki et al. 1984; Keller 2006; Bellevicine 2014; Mackenzie 2015; Tahmasebi 2015) diffuse B-cell lymphoma appears to be one of the more common subtypes (Komaki et al. 1984; Dyer et al. 2011; Vang et al. 2000, Bellevicine et al. 2014; Mandato et al. 2014; Adachi et al. 2015; Chen et al. 2015). Management of human uterine diffuse B-cell lymphoma commonly involves the use of CHOP chemotherapy plus Rituximab (CHOP-R) (Dyer et al. 2011; Mandato et al. 2014; Chen et al. 2015).

Lymphoma in companion animals is no longer considered a generic disease. There is marked variation in the biology of canine lymphomas that requires the treatment and management of each type of lymphoma to be carefully weighed (Vail et al. 2013). In both of these cases, progression of lymphoma led to the euthanasia of the dog. In Case 1, chemotherapy appeared to offer a survival advantage, although the rarity of this disease presentation precludes any meaningful conclusions regarding treatment outcomes. It is suggested to include lymphoma in the list of differential diagnoses in bitches with uterine masses.

\section{References}

Adachi S, Yamazaki K, Liang SG, Ishida Y 2015: Primary uterine diffuse large B-cell lymphoma involving the urinary bladder with urinary cytology mimicking carcinomas: A case report. J Cytol 32: 181

Bellevicine C, Zabatta A, Malapelle U, Vetrani A, Troncone G 2014: Diffuse Large B-Cell Extranodal Lymphoma of the Uterine Cervix. Diagn Cytopathol 42: 644-646

Burton AJ, Nydam DV, Long ED, Divers TJ 2010: Signalment and clinical complaints initiating hospital admission, methods of diagnosis, and pathological findings associated with bovine lymphosarcoma (112 cases). J Vet Intern Med 24: 960-964

Burton JH, Garrett-Mayer E, Thamm DH 2013: Evaluation of a 15-week CHOP protocol for the treatment of canine multicentric lymphoma. Vet Comp Oncol 11: 306-315

Carrasco V, Rodríguez-Bertos A, Rodríguez-Franco F, Wise AG, Maes R, Mullaney T, Kiupel M 2015: Distinguishing intestinal lymphoma from inflammatory bowel disease in canine duodenal endoscopic biopsy samples. Vet Pathol 52: 668-675

Chen R, Yu Z, Zhang H, Ding J, Chen B 2015: Primary malignant lymphoma of the uterus and broad ligament: a case report and review of literature. Onco Targets Ther 8: 265

Claes A, Ball BA, Liu IKM, Vaughan B, Highland MA, Brown JA 2015: Uterine B cell lymphoma in a mare. Equine Vet Educ 27: e5-e8

Díaz-Delgado J, Sierra E, Arbelo M, Suárez-Bonnet A, Suárez-Santana C, Grau-Bassas E, Fernández A 2015 : Primary uterine T-cell lymphoma with metastasis in an Atlantic spotted dolphin (Stenella frontalis), Canary islands, Spain. J Wildl Dis 51: 538-541

Dyer MJ, Ye H, Isaacson PG 2011: Primary lymphoma-like lesions of the uterine cervix; sheep in wolves' clothing. Br J Haematol 153: 791-794

Fontaine J, Heimann M, Day MJ 2010: Canine cutaneous epitheliotropic T-cell lymphoma: a review of 30 cases. Vet Dermatol 21: 267-275

Garrett LD, Thamm DH, Chun R, Dudley R, Vail DM 2002: Evaluation of a 6-month chemotherapy protocol with no maintenance therapy for dogs with lymphoma. J Vet Intern Med 16: 704-709

Hadi E, Bruchim I, Helman I, Shehtman I, Stackievicz R, Tepper R, Hershkovitz R 2015: Sonographic appearance of uterine lymphoma: Case report and review of the literature. J Clin Ultrasound 43: 59-63

Kaiser HE 1981: Animal neoplasms: A systemic review. In: Kaiser HE, ed. Neoplasms: Comparative Pathology in Animals, Plants, and Man. William \& Wilkins, Baltimore pp 747-812

Keller C, Savage DG, Rusta-Villa M, Bhagat G, Alobeid B 2006: Primary Burkitt lymphoma of the uterine corpus. Leuk Lymphoma 47: 141-145 
Ko JS, Kim HJ, Han S, Do SH 2013: Primary lymphoma of the uterine horn in a Lhasa Apso dog. Ir Vet J 66: 1

Komaki R, Cox JD, Hansen RM, Gunn WG, Greenberg M 1984: Malignant lymphoma of the uterine cervix. Cancer 54: 1699-1704

Mackenzie E, Towns C, Tiong S, Petrich S 2015: Primary endometrial uterine Burkitt lymphoma in a 65-year-old woman. Gynecologic oncology reports 13: 30-32

Mandato VD, Palermo R, Falbo A, Capodanno I, Capodanno F, Gelli MC, Aguzzoli L, Abrate M, La Sala GB 2014: Primary diffuse large B-cell lymphoma of the uterus: case report and review. Anticancer Res 34: 4377-4390

Morrison-Collister KE, Rassnick KM, Northrup NC, Kristal O, Chretin JD, Williams LE, Cotter SM, Moore AS 2003: A combination chemotherapy protocol with MOPP and CCNU consolidation (Tufts VELCAP-SC) for the treatment of canine lymphoma. Vet Comp Oncol 1: 180-190

Moulton JE, Harvey JW 1990: Tumors of the lymphoid and hematopoietic tissues. In: Moulton JE (Ed.): Tumors in Domestic Animals. $3^{\text {rd }}$ edn. Berkeley, University of California Press, pp 267-270

Mutz M, Boudreaux B, Kearney M, Stroda K, Gaunt S, Shiomitsu K 2015: Prognostic value of baseline absolute lymphocyte concentration and neutrophil/lymphocyte ratio in dogs with newly diagnosed multi-centric lymphoma. Vet Comp Oncol 13: 337-347

Olson C, Baumgartener LE 1976: Pathology of lymphosarcoma in sheep induced with bovine leukemia virus. Cancer Res 36: 2365-2373

Risbon RE, Lorimier LD, Skorupski K, Burgess KE, Bergman PJ, Carreras J, Hahn K, Leblanc A, Turek M, Impellizeri J, Wojcieszyn JW 2006: Response of canine cutaneous epitheliotropic lymphoma to lomustine (CCNU): a retrospective study of 46 cases (1999-2004). J Vet Intern Med 20: 1389-1397

Tanaka H, Takai H, Sato K, Ishikawa Y, Shibahara T, Kadota K 2003: Nodal, uterine and meningeal $\gamma \delta$ T-cell lymphomas in cattle. J Vet Med A Physiol Pathol Clin Med 50: 447-451

Taylor AJ, Lara-Garcia A, Benigni L 2014: Ultrasonographic characteristics of canine renal lymphoma. Vet Radiol Ultrasound 55: 441-446

Tahmasebi FC, Roy S, Kolitz JE, Sen F, Laser J, Zhang X 2015: Primary extranodal marginal zone lymphoma of the endometrium: report of four cases and review of literature. Int J Clin Exp Pathol 8: 3036

Vail DM, Pinkerton ME, Young KM 2013: Hematopoietic tumors. In: Small Animal Clinical Oncology. $5^{\text {th }}$ edn. St. Louis, Elsevier, pp. 608-638

Valli VE, San Myint M, Barthel A, Bienzle D, Caswell J, Colbatzky F, Durham A, Ehrhart EJ, Johnson Y, Jones C, Kiupel M 2011: Classification of canine malignant lymphomas according to the World Health Organization criteria. Vet Pathol 48: 198-211

Vang R, Medeiros LJ, Ha CS, Deavers M 2000: Non-Hodgkin's lymphomas involving the uterus: a clinicopathologic analysis of 26 cases. Mod Pathol 13: 19-28

Withrow SJ, Vail DM, Page LR 2013: Withrow and MacEwen's Small Animal Clinical Oncology. Saunders, Philadelphia, PA 
Plate V

Novotny L. et al.:Uterine B-cell... pp. 195-198

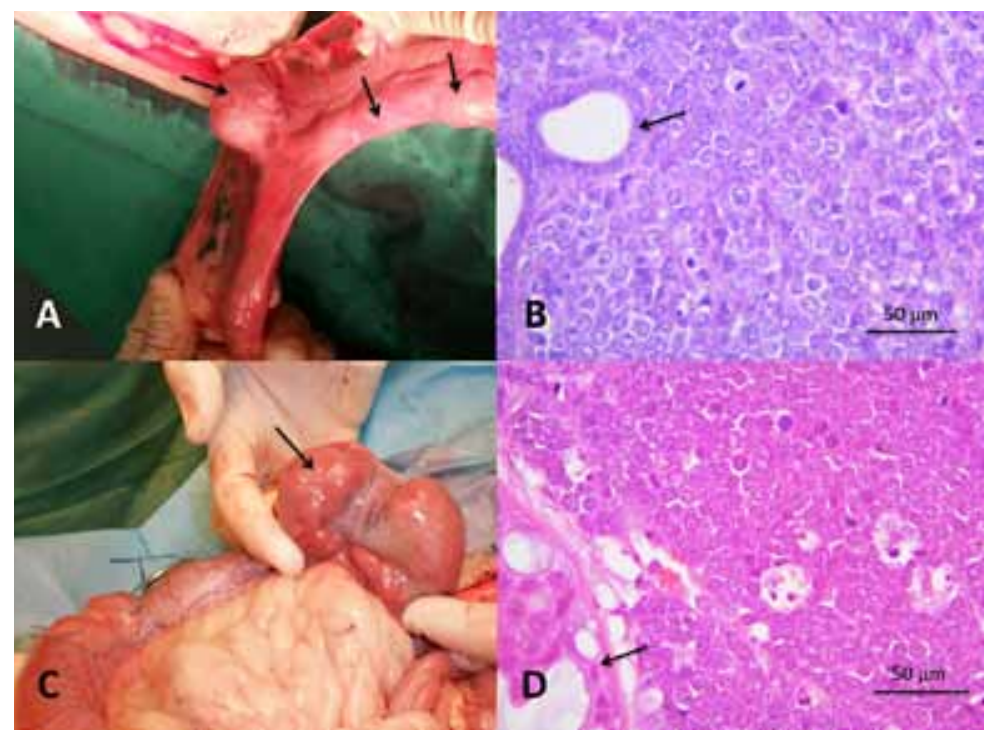

Fig. 1. A - German Short Hair Pointer: The uterine horns and body are expanded by multiple nodules (arrows). B - German Short Hair Pointer: The endometrium is expanded by sheets of large atypical lymphoid cells with vesicular nuclei, multiple nucleoli and 2-4 mitotic figures in one high power field (HPF). Occasional remaining endometrial glands are seen (arrow). C - Bernese Mountain Dog: The uterine horn contains multiple nodules (arrow). D - Bernese Mountain Dog: Sheets of lymphoid cells have very similar morphology as seen in the uterus of the German Short Hair Pointer. Mitotic activity was higher, 3-6/HPF. The arrow shows a residual endometrial gland.

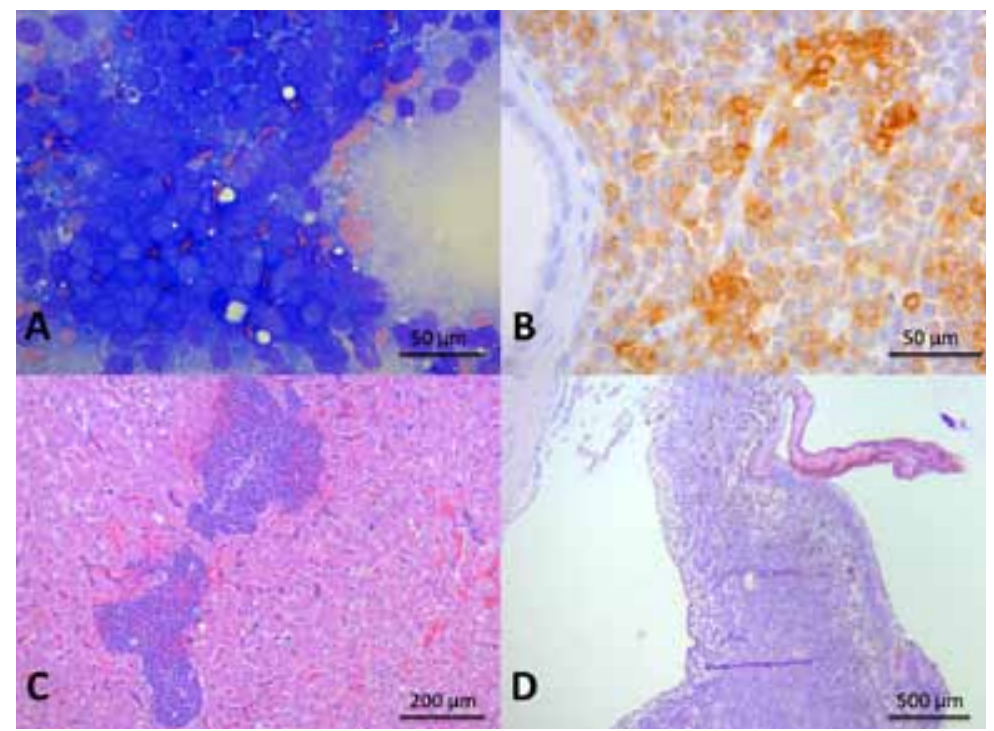

Fig. 2. A - German Short Hair Pointer: Fine needle aspirate from a nodule in the mammary gland contains sheets of large atypical lymphoid cells with multiple apoptotic bodies. B - German Short Hair Pointer: Uterus-endometrium. Immunohistochemistry, diffuse positivity for CD79a receptor. C - German Short Hair Pointer: Metastasis of lymphoma in the liver, expanding mainly portal areas. D - German Short Hair Pointer: Metastatic infiltration of the iris. 